Geografia e Ordenamento do Território, Revista Eletrónica

Centro de Estudos de Geografia e Ordenamento do Território

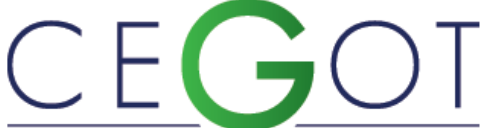

Centro de Estudos de Geografia e Ordenamento do Território

http://cegot.org

ISSN: 2182-1267

Martins, F.

Faculdade de Letras da Universidade do Porto - CEGOT

felisbela.martins@gmail.com

Correia, L.

Faculdade de Letras da Universidade do Porto - CITCEM

Igrosso@letras.up.pt

\title{
A formação de professores de História e Geografia na Faculdade de Letras da Universidade do Porto. 0 percurso à luz do processo de Bolonha (2008-2012).
}

Referência: Martins, F. Correia, L. (2012). A formação de professores de História e Geografia na Faculdade de Letras da Universidade do Porto. O percurso à luz do processo de Bolonha (2008-2012). Revista de Geografia e Ordenamento do Território, n. 1 (Junho). Centro de Estudos de Geografia e Ordenamento do Território. Pág. 127 a 142

\section{Resumo}

A formação inicial de professores de Geografia e História tem vindo a ser realizada na Faculdade de Letras da Universidade do Porto (FLUP) desde o ano de 1987/1988. Inicialmente a formação de professores de Geografia era realizada independentemente da formação de professores de História, mas à luz do Processo de Bolonha implementado em Portugal (Decreto - Lei n4/2007) resulta numa formação académica ao nível do Curso de Mestrado em Ensino da História e Geografia. Pretendemos dar a conhecer o estudo que temos vindo a desenvolver no sentido de 
compreender o modelo de formação inicial de professores, nas experiências desenvolvidas junto dos estudantes formados na FLUP. É um estudo empírico centrado na formação e nas representações e práticas desenvolvidas pelos estudantes, futuros professores.

Palavras-Chave: Formação Inicial de Professores, Geografia, História.

\begin{abstract}
The initial training of Geography and History teachers have been held at the Faculty of Arts, University of Porto (FLUP) since the year 1987/1988. Initially the teacher education of Geography was carried out independently of teacher education of History, but with the Bologna Process results in Portugal (Decree-Law No. 43/2007) an academic-level Master's Degree in Teaching History and Geography. In this paper we intend to present the study that we have been developing in this Faculty in order to understand the model of initial teacher training in Geography and History in the experiences of first generations of students trained in using the Bologna model at the FLUP's teacher education course. It is an empirical study focused on the training and the representations and practices developed by students, teachers of the future.
\end{abstract}

Keywords:. Initial Teachers Training, Geography, History. 


\section{Introdução}

A formação de professores nas áreas de Geografia e de História era tradicionalmente realizada, até 2008 , de forma independente e inseria-se numa lógica monodisciplinar que prolongava a licenciatura em duas formações educacionais distintas. O modelo seguido pela Faculdade de Letras da Universidade do Porto (FLUP) consistia numa formação docente com a duração total de cinco anos, ora integrando a componente de formação para a docência (Ramo Educacional), nos quais se inclui a realização do Estágio Pedagógico no último ano, ora, a partir de 2005, num modelo bietápico com um total de cinco anos - licenciatura (com uma duração de quatro anos) seguida de um curso de especialização em ensino.

Estes cursos pautavam-se por uma formação centrada nos primeiros anos na formação científica dos saberes geográficos e nos saberes históricos e a partir do 3ำ ano do curso de licenciatura iam-se focando numa formação educacional geral e didática especializada, que tentava articular a teoria com a prática, para terminar com a realização de um estágio em contexto de inserção profissional (escola) ao longo de um ano lectivo. Eram assim, tanto para a formação inicial de professores de Geografia como para os de História, cursos que se encontravam separados e independentes, apesar de formalmente se regularem por uma arquitetura curricular muito semelhante.

A partir de 2008/2009, e por via de imposição legal, o modelo de formação profissional resulta num curso em que as duas áreas científicas se apresentam, em correlação curricular, isto é, no Mestrado em Ensino de História e Geografia (MEHG).

O presente estudo insere-se na linha de outros que temos vindo a desenvolver ${ }^{1} \operatorname{com}_{0}$ intuito de gerir e qualificar um curso que foi administrativamente instituído pelo Ministério da Educação português. Pretende-se, assim, conhecer as implicações que o curso representa nos percursos escolares dos estudantes (desde o ensino secundário

\footnotetext{
${ }^{1}$ Cf., por exemplo, "Desembrulhando a formação de professores de História e Geografia no quadro do Processo de Bolonha em Portugal (estudo de caso)", comunicação apresentada à Conferencia Internacional Innovación metodológica y docente en Historia, Arte y Geografia, Universidade de Santiago de Compostela, 08.09.2011.
} 
até à entrada do MEHG), analisar a adequação curricular dos cursos de licenciatura em História e em Geografia na FLUP e avaliar o significado do curso na ótica das primeiras gerações de estudantes em curso. Estes tópicos vão ser desenvolvidos ao longo deste artigo, mas, antes porém, faremos uma breve contextualização teórica do papel do professor enquanto profissional, segundo a linha que nos orienta. Finalizaremos com considerações finais, já que este estudo se encontra em aberto e numa auscultação contínua.

\section{O professor como profissional reflexivo}

A ideia do professor que reflete na e sobre a ação, a do profissional que pensa refletindo, é desenvolvida por Donald Schön (1998), quando advoga que a ideia de reflexão na ação, é comum no dia-a-dia de prática profissional e que parte do conhecimento dos profissionais resulta da sua ação prática, efeito dos sucessivos e constantes processos de reflexão. O professor, ao refletir sobre a sua própria prática, transforma-a em objecto de questionamento com vista à melhoria das suas qualidades educativas.

Na mesma linha de pensamento, Henry Giroux realça o carácter intelectual de atividade do professor. Do seu ponto de vista, os professores devem ser capazes de "assumir responsabilidades ativas pelo levantamento de questões sérias acerca do que ensinar, como devem ensinar, e quais as metas mais amplas pelas quais estão lutando" (1997:161), com o objectivo de construir um ensino dirigido à transformação de cidadãos críticos e ativos. Nesta linha de pensamento, as escolas devem ser lugares onde os alunos aprendem de forma a tornar possível a liberdade individual e a capacidade para a atuação social. Desta forma, os docentes são encarados como "intelectuais transformadores" (Giroux, 1997:161) que ajudam os estudantes a adquirir um conhecimento crítico sobre as estruturas sociais básicas. Reconhece-se, e na opinião de Zeichner (1993:16), que os professores devem ser profissionais que desempenham "um papel ativo na formulação tanto dos propósitos e objectivos do seu trabalho como nos meios para os atingir", ou seja, "professores práticos reflexivos" (ibidem). 
Advogamos que o papel do professor não deve ser mais o convencional, mas sim o de um profissional que saiba ser um agente participante ativo e autónomo e que saiba responder às necessidades da escola em que exerce a profissão e dos alunos com quem trabalha. Advogamos o papel de professor que rompa com roturas e com a produção das situações de práticas instituídas. Faz então sentido repensar a formação de professores "que possibilite a aquisição e reconstrução de destrezas, conhecimentos e disposições para reinterpretar o currículo, o que requer uma maior participação dos professores no processo da sua construção e do seu desenvolvimento" (Flores, 2000). Então, deverá ser ultrapassada a formação de professores apenas centralizada na especialização dos saberes e nas técnicas e ser alargada e dar lugar a uma formação "que socializa os futuros professores com a profissão que thes permite desenvolver uma mentalidade curricular (entendida como consciência do sistema em que se está inserido e do papel, ou papéis, que nele desempenham, ou podem vir a desempenhar" (Leite, 2005a). Tem que ser pensada uma formação de professores de modo a "desenvolver uma formação potenciadora das atitudes de reflexão e análise permanente e critica da sua própria prática" (Garcia,1999:131).

As imagens de um professor que reflita sobre a sua ação e participe na sua formação implicam uma perspectiva de formação de professores que ultrapasse a relação "linear e hierárquica entre o conhecimento científico e a sua prática" (Flores, 2000:156). Além do mais, deve implicar, segundo Leite (2005c:372), ir mais além "dos conhecimentos disciplinares a que cada um/a se encontra veiculado/a, sem no entanto, os deixar de ter em conta" e conferir "novas profissionalidades que permitam que os professores desenvolvam competências para lidar com as situações que as mudanças sociais têm gerado" (ibidem). Como refere Flores (2000:156), uma "visão holística e integradora dos processos de formação, superando a perspectiva disciplinar, no sentido de uma atitude crítica fomentadora da dimensão auto -reflexiva do conhecimento".

Esta concepção de formação afasta-se da concepção qualificada do modelo tecnicista, para dar lugar a uma formação qualificante "que apoia uma investigação que por ser crítica e disfuncional, é, também ela qualificante (Correia,1998:140). Ao mesmo tempo esta concepção de formação de professores deve permitir desenvolver, uma tomada 
de consciência, sobre o papel que têm como agentes educadores e, como tal, devem de refletir e investigar sobre as suas próprias práticas. Entenda-se, neste caso, que as práticas não dizem respeito só ao seu trabalho na sala de aula, mas também fora dela. Ou seja, não entendemos uma formação de professores que permita só desenvolver boas práticas dentro da sala de aula e que ignore o seu trabalho dentro do contexto da escola e da comunidade. Entendemos, sim, uma formação de professores que vá mais longe e que permita desenvolver ações que levem os professores a colocar sistematicamente em questão o seu próprio ensino, que sejam capazes de eles próprios estudarem e investigarem modos de trabalho pedagógico de ensinar e de identificarem o interesse de o fazer. Uma formação de professores que desenvolva uma nova atitude pedagógica, que desenvolva uma nova forma de estar em educação. Ou seja, professores que sejam capazes de um desenvolvimento profissional autónomo, possuidores de atitudes de auto - análise atenta e permanente e onde não são ignoradas questões de ordem social.

\section{O Curso de Mestrado em Ensino de História e Geografia na}

\section{FLUP: da lei à prática}

O regime jurídico da habilitação para profissional para a docência na educação préescolar e nos ensinos básico e secundário (Decreto-Lei no 43/2007 de 22 de Fevereiro), institucionaliza os cursos de formação de professores em Portugal de acordo com o Processo de Bolonha.

Desta forma a formação de professores do 3 o ciclo do ensino básico e secundário em Portugal continua a ser assegurada por instituições do ensino superior universitário passando a ser realizadas no quadro de um curso de mestrado após uma licenciatura, em princípio, com a duração de 3 anos.

Apesar de anteriormente ter existido uma comissão técnica (Despacho $\mathrm{n}$ ㅇ 13766/2004), que reuniu com docentes de instituições do ensino superior politécnico e universitário ligados à formação inicial de professores, e esta ter emitido um parecer em que se destaca que "os candidatos a professores que pretendam fazer um curso de formação de professores do 3 ciclo do Ensino Básico e do Ensino Secundário devem 
fazer o 1 으 ciclo de estudos superiores na área disciplinar de docência, seja esta letras, ciências, artes plásticas, educação física ou outra" (Ponte, 2004), o que é certo é que as instituições formadoras tomaram conhecimento oficial de que a formação inicial de professores de História e Geografia do 3ํ ciclo do Ensino Básico e Ensino Secundário passa a fazer-se de uma forma integrada num único curso.

As autoridades educativas não prestaram qualquer informação sobre a opção política tomada e foi através do documento legal que foram conhecidos os critérios para a organização do Mestrado em Ensino da História e Geografia (Quadro 1).

Quadro 1: Princípios e critérios do MEHG segundo o Decreto-Lei no 43/2007, de 22 de Fevereiro.

\begin{tabular}{|l|l|}
\hline Especialidade do grau de mestre & Professor de História e Geografia. \\
\hline Domínios de habilitação para a docência & $3^{\circ}$ ciclo do ensino básico e ensino secundário \\
\hline Níveis e ciclos abrangidos & Ensino de História e de Geografia no 3.o Ciclo do Ensino Básico e no Ensino Secundário. \\
\hline $\begin{array}{l}\text { Créditos mínimos de formação na área } \\
\text { de docência para ingresso no ciclo } \\
\text { de estudo conducente ao grau de mestre }\end{array}$ & 120 créditos no conjunto das duas áreas disciplinares e nenhuma com menos de 50 créditos. \\
\hline
\end{tabular}

Estabeleceu-se, por outro lado, as componentes a observar na formação de professores de História e Geografia no 3ํ ciclo do Ensino Básico e Secundário, eram as respectivas proporções curriculares mínimas, as seguintes:
A) Formação educacional geral (25\%)
B) Didáticas específicas (25\%)
C) Iniciação à Prática Profissional (40\%)
D) Formação na área da docência (5\%)

O Decreto-Lei 43/2007 estipula que para se ingressar num Curso de Mestrado de Ensino da História e Geografia os candidatos devem possuir uma Licenciatura em Geografia com minor em História ou possuir uma Licenciatura em História com minor em Geografia.

No caso da FLUP, os candidatos têm que possuir 120 ECTS em Geografia mais 54 ECTS em História aos quais se juntam 6 ECTS de uma disciplina de opção ou 126 ECTS em História mais 54 ECTS em Geografia. Ou seja, ao nível da Licenciatura de Geografia com minor em História, os alunos têm vindo a frequentar um curso de 3 anos com oito áreas científicas de formação geográfica e, a partir do $2 \cong$ semestre do 20 ano, um conjunto de 9 unidades curriculares que perfazem o minor em História (Quadro 2). 
Quadro 2: Plano de estudos do minor em História do curso de licenciatura em Geografia.

\begin{tabular}{|c|l|l|}
\hline Anos & \multicolumn{1}{|c|}{$1^{\circ}$ Semestre } & \multicolumn{1}{c|}{$2^{\circ}$ Semestre } \\
\hline \multirow{2}{*}{$2^{\circ}$ Ano } & & História Económica e Social na Época Medieval \\
\cline { 3 - 3 } & & História Medieval de Portugal \\
\hline \multirow{3}{*}{$3^{\circ}$ Ano } & História Económica e Social na Época Moderna & História dos Descobrimentos e da Expansão Portuguesa \\
\cline { 2 - 3 } & História Moderna de Portugal & História Contemporânea de Portugal \\
\cline { 2 - 3 } & História Económica e Social na Época Contemporânea & História da Historiografia \\
\cline { 2 - 3 } & Métodos e Técnicas de Investigação Histórica & \multicolumn{2}{|l}{} \\
\hline
\end{tabular}

No caso da licenciatura em História com minor em Geografia os estudantes frequentam disciplinas de oito componentes científicas de formação histórica e podem escolher 9 entre uma oferta de 14 unidades curriculares opcionais no minor de Geografia nos dois semestres do 2ㅇ e 3ㅇ anos do curso ${ }^{2}$ (Quadro 3).

Quadro 3: Plano de estudos do minor em Geografia do curso de licenciatura em História.

\begin{tabular}{|c|l|l|}
\hline Anos & \multicolumn{1}{|c|}{$1^{\circ}$ Semestre } & \multicolumn{1}{c|}{$\mathbf{2}^{\circ}$ Semestre } \\
\hline \multirow{3}{*}{$2^{\circ}$ e $3^{\circ}$ Anos } & Cartografia & Desenvolvimento e Planeamento do Território \\
\cline { 2 - 3 } & Geografia da Europa & Geografia da População \\
\cline { 2 - 3 } & Geografia Física de Portugal & Geografia Humana de Portugal \\
\cline { 2 - 3 } & Geografia Rural & Processos Atmosféricos e Hidrológicos \\
\cline { 2 - 3 } & Geografia Urbana & Processos Ecológicos da Biosfera \\
\cline { 2 - 3 } & Mudanças Globais e Ambiente & Processos Geomorfológicos \\
\cline { 2 - 3 } & Pensamento Geográfico & \\
\cline { 2 - 3 } & Sociedade, Território e Globalização & \\
\hline
\end{tabular}

Concluídas estas licenciaturas, os estudantes ingressam no mestrado em ensino. Este curso pós-graduado integra disciplinas das áreas de formação educacional geral e das didáticas específicas distribuídas por dois semestres do 1을 ano. 0 2으 ano é dominado pela unidade curricular de Iniciação à Prática Profissional (IPP) que compreende as componentes de Prática de Ensino Supervisionada (PES) que se realiza nas escolas básicas e secundárias e de Seminário Integrador de História e Geografia, que semanalmente e de modo alternado entre Geografia e História, que se realiza na FLUP (Figura 1).

Os estudantes que frequentam o 2ㅇ ano do Mestrado, de acordo com o Regulamento específico da IPP, realizam a sua Prática de Ensino Supervisionada (vulgo estágio) em

\footnotetext{
${ }^{2}$ A partir do ano letivo de 2012/2013 este leque de opções diminuirá para 11.
} 
escolas do ensino básico e secundário e devem ainda construir um relatório final de estágio, que é objecto de discussão pública por um júri, e deverá articular-se com uma temática original trabalhada na prática docente.

Assistimos, assim, à construção de um curso assente em dois cursos de licenciatura (História e Geografia) que são estruturados por corpos epistemológicos e metodológicos distintos, não obstante as pontes e interseções que é sempre possível estabelecer.

Figura 1: Plano de estudos do curso de MEHG da FLUP.

\section{Área}

\begin{tabular}{|l|}
\hline Formação \\
Educacional \\
Geral
\end{tabular}

\begin{tabular}{|l|}
\hline Formação \\
Didáctica \\
Específica \\
\hline
\end{tabular}
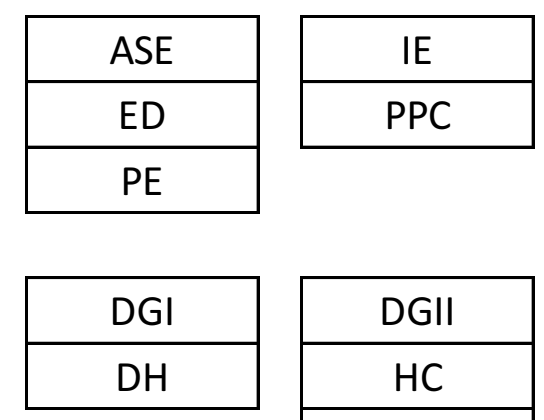

20 Sem. 10 Sem.

10 Ano
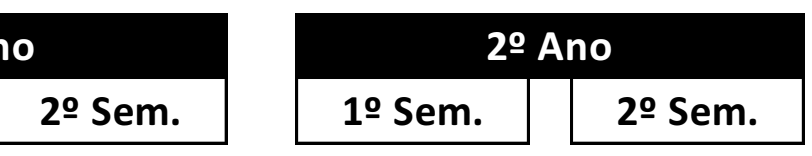

10 Sem.

20 Sem.

\section{Iniciação à \\ Prática \\ Pedagógica}

\section{F. Científica}

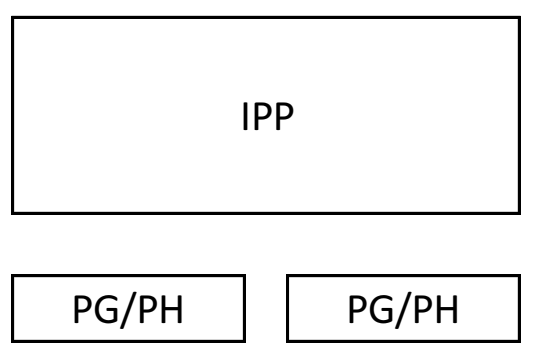

Legenda: ADHG - Aplicações Didáticas em História e Geografia; ASE - Análise Social da

Educação; DG I - Didática da Geografia I; DG II - Didática da Geografia II; DH - Didática da História; ED - Ética e Deontologia; HC - História e Cidadania; IE - Investigação Educacional; IPP Iniciação à Prática Pedagógica; PG - Problemáticas Geográficas; PH - Problemáticas de História; PPC - Problemáticas Pedagógicas Contemporâneas; PE - Psicologia da Educação. 


\section{Os estudantes e as suas representações face ao MEHG.}

A investigação encetada com o objetivo de melhor se compreender e gerir o novel modelo de formação inicial de docentes decretado em 2007 é fundamentada na análise de documentos e inquéritos aplicados em junho de 2010 e 2011 aos estudantes das três primeiras edições (de 2008/2009, 2009/2010 e de 2010/2011) do curso de Mestrado em Ensino de História e Geografia. Temos por finalidade identificar os perfis de entrada dos alunos, analisar a percepção, expectativas, experiência, satisfação e representação dos alunos, otimizar a organização e desenvolvimento curricular, as experiências de formação e os limitados recursos docentes disponíveis, contribuir para a qualificação da formação científica, educacional e pedagógica dos estudantes/futuros docentes de Geografia e de História.

Como já dissemos anteriormente, o Curso de MEHG para o 3 ciclo do Ensino Básico e Secundário teve o seu início na FLUP no ano lectivo de 2008/2009. Constatamos, muito do que já tínhamos verificado no nosso trabalho diário. Constatamos que o perfil da população do curso nos três primeiros anos do seu funcionamento é dominado por estudantes com um intervalo de idades entre os 21 e os 48 anos e a idade média é de 28,1 anos. Para além da idade há uma proporção muito significativa dos respondentes ser trabalhadora (22 casos ou $41,5 \%$ ).

Desde esse ano até à atualidade inscreveram-se no curso 94 alunos (cf. Quadro 4), dos quais salientamos os 23 casos de estudantes com habilitação profissional docente em Geografia e os 7 casos de estudantes oriundos de outras licenciaturas correlacionadas com as Ciências Sociais (Relações Internacionais, Antropologia, Sociologia, Ciências Religiosas, entre outras). 
Quadro 4 - Alunos inscritos no MEHG de 2008/09 a 2011/12

\begin{tabular}{|l|c|c|c|c|c|}
\hline Estudantes & $\mathbf{2 0 0 8 / 0 9}$ & $\mathbf{2 0 0 9 / 1 0}$ & $\mathbf{2 0 1 0 / 1 1}$ & $\mathbf{2 0 1 1 / 1 2}$ & Total \\
\hline Matrículas & 13 & 30 & 51 & 68 & 162 \\
\hline Estudantes 10 Ano-19 Vez & 13 & 20 & 29 & 32 & 94 \\
\hline Geografia & 8 & 3 & 8 & 9 & 28 \\
\hline História & 3 & 14 & 6 & 11 & 34 \\
\hline Geografia - Profissionalizado & 2 & 2 & 11 & 8 & 23 \\
\hline História - Profissionalizado & - & 1 & - & 1 & 2 \\
\hline Outros Cursos & - & - & 4 & 3 & 7 \\
\hline Docentes Profissionalizados & - & 4 & 10 & {$[8+20]$} & $14[+28]$ \\
\hline
\end{tabular}

Os 25 itens do inquérito (desdobrados num total de 55 sub-itens) por nós aplicado foram preenchidos por 53 respondentes, na sua maioria mulheres e licenciados em História. O perfil académico das famílias de origem dos estudantes do MEHG demonstra o predomínio das habilitações inferiores ao nível do ensino secundário (75,4\% para os pais e $72,4 \%$ para as mães), padrão este que poderá aproximar-nos do terreno cultural de origem e das expectativas dos estudantes face ao curso de MEHG.

Não obstante o facto de os estudantes serem originários de cursos de licenciatura diferentes, com, eventualmente, culturas epistemológicas, metodológicas e pedagógicas diferenciadas (como é o caso da História e da Geografia), é curioso constatar que a classificação média final de licenciatura com que os estudantes se candidataram ao MEHG é muito equilibrada $(13,6)$.

A adesão dos respondentes ao curso de MEHG parece adquirida logo à entrada do mesmo se tomarmos em consideração a ordem dos critérios invocados/selecionados como mais representativos da sua candidatura: adequação a características e projetos pessoais, motivação científico-profissional para a docência, estabilidade profissional (Quadro 5). 
Quadro 5-Critérios que presidiram à opção dos respondentes pelo curso de MEHG

\begin{tabular}{|l|c|c|}
\hline Opção pelo curso de MEHG & $\%$ & Ordem \\
\hline 17.1. É o curso que melhor se adequa às minhas características pessoais & 82.7 & 1 \\
\hline 17.2. Porque fiquei excluída/o de outro curso de mestrado & 25.0 & 8 \\
\hline 17.3. É o curso que melhor se adequa aos meus projetos pessoais & 82,7 & 1 \\
\hline 17.4. É o curso em que mais elevadas classificações se obtém & 26,9 & 6 \\
\hline 17.5. É o curso, entre as opções de escolha, considero ser “um mal menor" & 26,9 & 6 \\
\hline 17.6. É o curso que mais desafios científicos, formativos e profissionais me lança & 65,4 & 3 \\
\hline 17.7. É o curso que me permitirá uma maior estabilidade profissional & 53,8 & 4 \\
\hline 17.8. É o curso que me foi aconselhado pelas outras pessoas & 34,6 & 5 \\
\hline 17.9. Outro critério & 5,8 & 9 \\
\hline
\end{tabular}

No nosso inquérito questionamos ainda os estudantes no sentido de conhecermos a assertividade do plano de estudos do mestrado, da pertinência e sequência das suas unidades curriculares ou de outras unidades curriculares. As respostas a estes itens revelaram como principais tendências a necessidade de o curso se concentrar sobre as áreas das componentes didática e científica e, neste sentido, operar alterações pontuais no plano de estudos (cf. Quadro 6 e Figura 2).

As opiniões dos respondentes constituem-se mais como um corpo de observações críticas organizado em torno de quatro núcleos:

- Curso demasiado "teórico", "técnico", "exigente", "trabalhoso", "uma continuação da licenciatura", sobretudo no seu 1ㅇano curricular;

- Imprimir uma formação "mais prática" no 10 ano e articular os trabalhos pedidos nas diferentes unidades curriculares do 1ㅇano;

- O plano de estudos está "desalinhado" no que concerne à componente científica do curso;

- A carga horária é excessiva no 1ำ ano e difícil de se compatibilizar com os horários laborais dos trabalhadores-estudantes. 
Quadro 6: Opinião dos respondentes sobre a pertinência das unidades curriculares do curso de MEHG e de outras unidades curriculares (a fundo cinzento) para a sua formação (em \%).

\begin{tabular}{|c|c|}
\hline Unidades Curriculares do Curso & $\%$ \\
\hline Didática da Geografia I & 100.0 \\
\hline Didática da História & 100.0 \\
\hline Iniciação à Prática Pedagógica & 100.0 \\
\hline Didática da Geografia II & 98.0 \\
\hline Problemáticas da Geografia & 93.9 \\
\hline Problemáticas da História & 91.8 \\
\hline Aplicações Didáticas em História e Geografia & 89.8 \\
\hline Psicologia da Educação & 87.8 \\
\hline Análise Social da Educação & 79.6 \\
\hline Didática da História II & 77.6 \\
\hline Investigação Educacional & 73.5 \\
\hline Ética e Deontologia & 67.3 \\
\hline Problemáticas Pedagógicas Contemporâneas & 61.2 \\
\hline Tecnologias de Educação e Comunicação em Educação & 44.9 \\
\hline História e Cidadania & 28.6 \\
\hline Organização e Desenvolvimento Curricular & 28.6 \\
\hline Educação e Cidadania & 20.4 \\
\hline Outras disciplinas & 20.4 \\
\hline Introdução às ciências da Educação & 16.3 \\
\hline
\end{tabular}


Figura 2: Plano de estudos do curso de MEHG segundo a opinião dos respondentes.

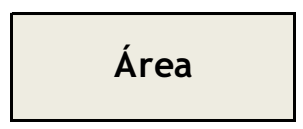

\begin{tabular}{|l|}
\hline Formação \\
Educacional \\
Geral
\end{tabular}

Formação

Didáctica

Específica

F. Científica

\section{$1^{\circ}$ Ano}

$1^{\circ} \mathrm{Sem} . \quad 2^{\circ} \mathrm{Sem}$.

\begin{tabular}{|c|}
\hline $\mathrm{IE}$ \\
\hline $\mathrm{PPC}$ \\
\hline
\end{tabular}

$2^{\circ}$ Ano

$1^{\circ}$ Sem. $\quad 2^{\circ}$ Sem.

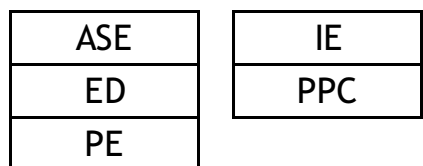

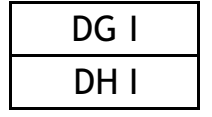
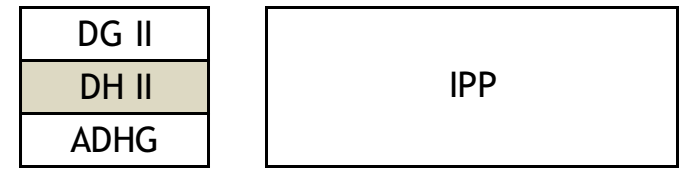

PG/PH

\section{PG/PH}

Legenda: ADHG - Aplicações Didáticas em História e Geografia; ASE - Análise Social da Educação; DG I - Didática da Geografia I; DG II - Didática da Geografia II; DH I - Didática da História I; ; DH II - Didática da História II; ED - Ética e Deontologia; IE - Investigação Educacional; IPP - Iniciação à Prática Pedagógica; PG - Problemáticas Geográficas; PH Problemáticas de História; PPC - Problemáticas Pedagógicas Contemporâneas; PE - Psicologia da Educação.

\section{Considerações finais}

Das opiniões emitidas pelos estudantes reconhecemos alguns padrões de opinião. Os estudantes estão preocupados com a validade da sua formação científica (minor) para intervir ao nível da respectiva docência da disciplina curricular no 30 ciclo do ensino básico e no ensino secundário. Daí se compreender a maior sensibilidade dos inquiridos, em especial os licenciados em História no que concerne à sua formação no minor em Geografia, para com o aprofundamento da sua formação científica em História e Geografia durante o 1 으 ano do MEHG. Defendem implicitamente, desta forma, o princípio da identidade docente construída em torno de uma elevada proficiência científica. Sobre a pertinência das unidades curriculares do curso para a sua formação as opiniões dos estudantes denotam uma atitude que se poderá rotular de "clássico". Ou seja, perante a sua formação dual do ponto de vista científico, interessa-lhes de igual modo aprofundar a sua formação na didática específica da Geografia e da História. Neste quadro tornam-se inteligíveis os resultados superiores a 75\% obtidos pelas unidades curriculares, existentes ou a introduzir, da formação didática (e educacional geral do curso segundo a opinião dos estudantes. O desenho 
curricular proposto pelos estudantes inquiridos para o MEHG é, neste quadro, também algo conservador. Os estudantes poucas alterações operariam nas unidades curriculares do curso com exceção da criação da Unidade Didática História II. No entanto, operariam alterações significativas no alinhamento dessas unidades do interior do MEHG ao fazerem derivar do $2^{\circ}$ ano para 10 ano as disciplinas da área científica (Problemáticas de Geografia e de Problemáticas de História).

Eis-nos pois perante vozes que enfatizam, porque assim sentem, a necessidade de uma formação profissional centrada nos saberes disciplinares, em especial na área do minor que frequentam. Se bem que identifiquem um reforço no campo das didáticas específicas estão longe de se aperceber que a sua formação tem de ser mais ampla, estão longe de se assumir como jovens professores com capacidade de adoptar uma atitude investigativa em relação ao seu próprio modo de ensinar (Stenhouse, 1987), ou de refletir sobre a sua própria prática (Schön, 1998; Zeichner, 1993). A constatação por parte destes alunos, face ao estádio de desenvolvimento dos seus conhecimentos científicos, não os deixa perceber e aperceber que a formação de professores em que estão inseridos vai e tem de ir mais longe do que uma formação centrada exclusivamente em saberes disciplinares ou de didáticas específicas.

E isto levanta problemas complexos dado os estudantes posicionarem-se como meros (e inseguros) receptores do conhecimento, o que conduz a uma concepção tecnicista da formação em detrimento de uma visão holística e investigadora dos processos de formação, que devem ultrapassar a perspectiva disciplinar desenvolvendo uma atitude crítica e, no mínimo, pluridisciplinar.

Se bem que tenhamos já ensaiado um breve diálogo entre os saberes pedagógicodidáticos desenvolvidos nestas ciências, a própria estrutura do curso, tem-nos condicionado profundamente. Por isso, questionamo-nos permanentemente por que caminhos enveredar, face os textos produzidos pelas autoridades legais, pelos teóricos e pelas instituições sobre a formação inicial de professores, a cultura docente imersa na prática pedagógica das escolas e as vozes dos estudantes do MEHG? 


\section{Referências bibliográficas}

Flores, M. A. (2000). Currículo, formação e desenvolvimento profissional in J.A. Pacheco, J.A. (org.). Políticas de Integração Curricular. Porto, Porto Editora: 147-165. Correia, J. A. (1998). Para uma teoria Crítica em educação Porto: Porto Editora, 208p. Garcia, C. M. (1999). Formação de Professores. Para uma mudança educativa Porto: Porto Editora, 272p.

Giroux, H. A. (1997). Os professores como intelectuais. Rumo a uma pedagogia crítica da aprendizagem. Porto Alegre, ARTMED Editora, 336p.

Leite, C. (2005a). O Currículo e o exercício profissional docente face aos desafios sociais desta transição de século in Ferraço, C. E. (org) (2005). Cotidiano escolar, formação de professores (as) e currículo. Cortez Editora:128-139.

Leite, C. (2005c). "Percursos e tendências recentes da formação de professores em Portugal", Educação, Porto Alegre-RS, ano XXVIII, no3 (57): 371 -389.

Ponte, J. Pedro et al. (2004), "A Formação de Professores e o Processo de Bolonha. Parecer sobre a implementação do Processo de Bolonha na área de Formação de Professores elaborado ao abrigo do Despacho n.ำ13 766/2004 da Ministra da Ciência e do Ensino Superior", publicado no Diário da República, II série, em 13 de Julho de 2004: 10579-80. Lisboa: ed. autor.

Schön, D. (1998). El Profesional reflexivo : cómo piensan los profesionales cuando actúan Barcelona: Paidós, 319 p.

Stenhouse, L. (1987). Investigación y desarrollo del curriculum. Madrid, Morata, 319 p. Zeichner, K. (1993). A formação Reflexiva de Professores: Ideias e Práticas. Lisboa, Educa, 131p. 